\title{
Left atrium remodeling predicts late recurrence of paroxysmal atrial fibrillation after second generation cryoballoon ablation
}

Andreea Motoc ${ }^{*}$ (D), Juan-Pablo Abugattas², Bram Roosens', Esther Scheirlynck ${ }^{1}$, Benedicte Heyndrickx ${ }^{1}$, Carlo de Asmundis ${ }^{2}$, Gian-Battista Chierchia ${ }^{2}$, Steven Droogmans ${ }^{1+}$ and Bernard Cosyns ${ }^{1+}$

\begin{abstract}
Background: Atrial fibrillation (AF) is the most common arrhythmia worldwide. Nowadays, AF ablation is a valuable treatment option. It has been shown that the left atrium (LA) diameter is a predictor of AF recurrence after cryoballoon ablation (CBA). Since it does not reflect the true LA size, we compared the role of different LA anatomical parameters using echocardiography for the prediction of AF recurrence after CBA.

Methods: We retrospectively included 209 patients (mean age $56.1 \pm 13.6$ years, male 62\%) with paroxysmal AF undergoing CBA. A transthoracic echocardiography was performed in all patients.

Results: At a mean follow-up of $16.9 \pm 6.3$ months, AF recurred in $25.4 \%$ of the patients. LA anterior - posterior diameter $(L A D), L A$ minimum volume ( $L A m i n)$ and early $A F$ recurrence were independent predictors of recurrence. Based on receiver operating characteristics, cut - off values for $L A D$ and, LAmin were $41 \mathrm{~mm}, 23.69 \mathrm{~mL}$, respectively. The negative predictive values for recurrence were $73 \%$ and $87.3 \%$ respectively. In patients with AF recurrence, a significant proportion (30.2\%) showed LA longitudinal remodeling (LA superior - inferior diameter) even though classically measured LAD was normal.

Conclusions: Longitudinal LA remodeling plays an additional role for predicting AF recurrence after CBA, in patients without LAD dilation. Moreover, LAmin had a high negative predictive value and was an independent predictor of AF recurrence. Therefore, a more complete LA anatomical assessment allows a better prediction of AF recurrences after CBA.
\end{abstract}

Keywords: Atrial fibrillation, Cryoballoon ablation, Left atrium, Echocardiography

\section{Background}

Atrial fibrillation (AF) is the most common cardiac arrhythmia, with an increasing frequency worldwide, and it is associated with an elevated risk for stroke, heart failure and mortality. Its prevalence in developed countries is currently estimated to $1.5-2 \%$ of the general population [1]. Resinusalisation is one of the main goals in AF patients. Several ablation strategies have proven to

\footnotetext{
* Correspondence: andreea.motoc@gmail.com

† Steven Droogmans and Bernard Cosyns contributed equally to this work. ${ }^{1}$ Centrum Voor Hart-en Vaatziekten (CHVZ), Department of Cardiology, UZ Brussel, Laarbeeklaan 101, 1090 Brussels, Belgium

Full list of author information is available at the end of the article
}

be efficient in the treatment of $\operatorname{AF}[2,3]$. Among them, one of the most promising and effective approaches is the second generation cryoballoon ablation (CBA) (Arctic Front Advance, Medtronic). However, up to $20 \%$ of patients experience AF recurrence after CBA $[4,5]$.

Recent data have shown that an increase of the left atrium (LA) anterior - posterior diameter (LAD) assessed by echocardiography is a powerful predictor of recurrence after CBA $[4,6]$. A possible explanation for the recurrence of AF could be the presence of myocardial fibrosis and remodeling of the LA [7]. However, LAD does not reflect the true size of the LA $[8,9]$. We hypothesized that a more complete analysis of the LA dimensions could be a

(c) The Author(s). 2018 Open Access This article is distributed under the terms of the Creative Commons Attribution 4.0 International License (http://creativecommons.org/licenses/by/4.0/), which permits unrestricted use, distribution, and reproduction in any medium, provided you give appropriate credit to the original author(s) and the source, provide a link to the Creative Commons license, and indicate if changes were made. The Creative Commons Public Domain Dedication waiver (http://creativecommons.org/publicdomain/zero/1.0/) applies to the data made available in this article, unless otherwise stated. 
better predictor of AF recurrence after CBA. Therefore, we compared the role of different anatomical parameters of the LA measured by echocardiography for predicting the recurrence of AF after CBA.

\section{Methods}

\section{Patient characteristics}

We retrospectively included 209 patients having undergone CBA for paroxysmal AF in our center from January 2014 to February 2016.

Baseline demographic characteristics can be found in Table 1. $\mathrm{CHA}_{2} \mathrm{DS}_{2}$-VASc score was calculated according to European Society of Cardiology Guidelines [1].

The study was approved by the local Ethical Committee and was carried out in accordance with the ethical principles for medical research involving human subjects established by Helsinki's Declaration, protecting the privacy of all participants, as well as the confidentiality of their personal information. All patients provided written informed consents.

\section{Transthoracic echocardiography}

A comprehensive transthoracic echocardiography (TTE) (using GE Vingmed Ultrasound, Vivid E9, Horten, Norway; Phillips Epiq, Philips, Andover, Massachusetts) was performed in all patients, according to the recommendations $[10,11]$. Standard parasternal long and short axis views and apical two-, three - and four - chamber views were available in all patients. Left ventricular (LV) dimensions were measured using $\mathrm{M}$ - Mode in the parasternal long axis view. LAD was measured using anatomical M-mode and two - dimensional assessment (2D) in the parasternal long axis view. LA maximum (LAmax) and minimum (LAmin) volumes were measured in two - and four chamber views, using the biplane area-length method (Fig. 1). LA volumes were indexed based on the patient's body surface area. Left atrium superior - inferior diameter was measured in apical two - and four chamber views (Fig. 2). Doppler mitral inflow peak early diastolic (E), peak atrial systolic velocities (A) and deceleration time were measured. Tissue Doppler imaging at the level of the mitral annulus was used to measure peak early diastolic septal and lateral e', as well as peak late diastolic a, corresponding to the P-wave on the electrocardiogram (ECG) $[10,12]$.

To determine the reproducibility of the LAD, LA superior - inferior diameter, LAmax and LAmin, the measurements were repeated in 20 randomly selected patients by an additional investigator and by the same primary investigator 1 week later. During the repeated analysis, the investigators were blinded to the results of all previous measurements.

\section{Pre-procedural management}

The antiarrhythmic drugs (AADs) were discontinued at least 3 days before the procedure, except for amiodarone, which was stopped one month before.

\section{Cryoballon ablation procedure}

Our standard ablation procedure has been previously reported in detail [13]. Briefly, after obtaining LA access, through a steerable $15 \mathrm{Fr}$ sheath (FlexCath Advance, Medtronic $\odot$ ), an inner lumen mapping catheter (ILMC) (Achieve ${ }^{\circ}$, Medtronic $\left.^{\circ}\right)$ was advanced in each pulmonary vein (PV) ostium and baseline electrical information was gathered. Optimal vessel occlusion was considered as achieved upon selective contrast injection showing total contrast retention with no backflow into the atrium. Once occlusion was documented, cryothermal energy was started for at least $180 \mathrm{~s}$. Usually, the PVs were treated as follows: first, the left superior PV (LSPV), then the left inferior (LIPV), right inferior (RIPV) and right superior (RSPV). PV activity was recorded with the ILMC at a proximal site within the ostium prior to ablation in each vein. If PV potentials (PVPs) were visible during energy delivery, time to isolation was recorded as the time from the start of the cryoenergy application until the PVPs completely disappeared or were dissociated from LA activity. In cases of phrenic nerve palsy (PNP), recovery of diaphragmatic contraction was carefully monitored for $30 \mathrm{~min}$. Further additional cryoenergy applications were not applied if the veins were isolated after the initial freeze. If needed, pacing from the distal and/or proximal coronary sinus was performed to recognise far field atrial signals from PVPs recorded on the mapping catheter. During the whole procedure, activated clotting time was maintained $>250$ s. In order to avoid phrenic nerve palsy, diaphragmatic stimulation was achieved by pacing the phrenic nerve during septal pulmonary veins ablations.

\section{Postablation management}

Patients were discharged the day after ablation if the clinical status was stable. Following the procedure, all the patients were continuously monitored with ECG telemetry for at least $18 \mathrm{~h}$. Oral anticoagulation was not discontinued for the ablation and continued for at least 2 months following the $\mathrm{CHA}_{2} \mathrm{DS}_{2}$ - VAsc score. During the blanking period (BP), AADs were continued. The decision to continue AADs after the BP or to perform a repeat procedure was taken if a first episode of recurrence of AF occurred.

\section{Follow-up}

All the included patients underwent physical examination and a $24 \mathrm{~h}$ Holter recording at 1, 3, 6 and 12 months after the ablation. Additional Holter 
Table 1 Baseline clinical and demographic characteristics

\begin{tabular}{|c|c|c|c|c|}
\hline Characteristic & Study population $(n=209)$ & AF recurrence $-(n=156)$ & AF recurrence $+(n=53)$ & $P$ value \\
\hline Age (y) & $56.1 \pm 13.5$ & $55.6 \pm 13.5$ & $57.4 \pm 13.7$ & 0.335 \\
\hline Male gender $(n, \%)$ & $130(62.2)$ & $98(62.8)$ & $32(60.4)$ & 0.753 \\
\hline Body mass index $\left(\mathrm{kg} / \mathrm{m}^{2}\right)$ & $26.5 \pm 4.7$ & $26.3 \pm 4.5$ & $27 \pm 5.3$ & 0.549 \\
\hline Tobacco use $(n, \%)$ & $52(24.8)$ & $35(28.8)$ & $17(32)$ & 0.281 \\
\hline Hypertension ( $n, \%)$ & $86(41.1)$ & $59(37.8)$ & $27(50.9)$ & 0.094 \\
\hline Diabetes $(n, \%)$ & $16(7.7)$ & $9(5.8)$ & $7(13.2)$ & 0.079 \\
\hline Dyslipidemia (n, \%) & $75(35.9)$ & $55(35.3)$ & $20(37.7)$ & 0.747 \\
\hline History of heart failure $(n, \%)$ & $6(2.9)$ & $4(2.6)$ & $2(3.8)$ & 0.651 \\
\hline Coronary artery disease $(n, \%)$ & $15(7.2)$ & $10(6.4)$ & $5(9.4)$ & 0.464 \\
\hline History of $\operatorname{TIA}^{\mathrm{a}} / \mathrm{CVA}^{\mathrm{b}}(n, \%)$ & $19(9.1)$ & $15(9.6)$ & $4(7.5)$ & 0.653 \\
\hline \multicolumn{5}{|l|}{ Failed drugs before ablation } \\
\hline Flecainide $(n, \%)$ & $46(22)$ & $31(19.8)$ & 15(28.3) & 0.177 \\
\hline $\operatorname{Propafenone}(n, \%)$ & $1(0.47)$ & $0(0)$ & $1(1.8)$ & 0.083 \\
\hline Amiodarone $(n, \%)$ & $9(4.3)$ & $6(3.8)$ & $3(5.6)$ & 0.555 \\
\hline Sotalol $(n, \%)$ & $24(11.4)$ & $16(10.2)$ & $8(15)$ & 0.316 \\
\hline Metoprolol $(n, \%)$ & $2(0.9)$ & $2(1.2)$ & $0(0)$ & 0.412 \\
\hline Bisoprolol (n, \%) & $78(37.3)$ & $57(36.5)$ & $21(39.6)$ & 0.620 \\
\hline Nebivolol $(n, \%)$ & $6(3.8)$ & $5(3.2)$ & $1(1.8)$ & 0.632 \\
\hline $\mathrm{ACE}^{\mathrm{C}}$ inhibitors before ablation & $26(12.4)$ & $20(12.8)$ & $6(11.3)$ & 0.809 \\
\hline ARBs $^{d}$ before ablation & $11(5.2)$ & $9(5.7)$ & $2(3.7)$ & 0.592 \\
\hline Prior ablation & 39 (18.6) & $29(18.5)$ & $10(18.8)$ & 0.547 \\
\hline - AVNRT & $13(6.2)$ & $12(7.7)$ & $1(1.9)$ & 1.000 \\
\hline - Right atrial flutter & $13(6.2)$ & $8(5.1)$ & $5(9.4)$ & 1.000 \\
\hline$-A F^{f}$ & $11(5.3)$ & $8(5.1)$ & $3(5.7)$ & 1.000 \\
\hline - Other & $2(1.0)$ & $1(0.6)$ & $1(1.9)$ & 1.000 \\
\hline $\mathrm{CHA}_{2} \mathrm{DS}_{2}$-VAsc score & $1.3 \pm 1.4$ & $1.2 \pm 1.3$ & $1.6 \pm 1.7$ & 0.134 \\
\hline Oral anticoagulation $(n, \%)$ & $60(28.7)$ & $41(26.3 \%)$ & $19(35.8 \%)$ & 0.552 \\
\hline Aspirin ( $n, \%)$ & $23(11)$ & $17(10.9)$ & $6(11.3)$ & 0.874 \\
\hline Follow-up duration (months) & $16.8 \pm 6.3$ & $16.9 \pm 5.7$ & $16.6 \pm 7.7$ & 0.795 \\
\hline Re-do ablation & $31(14.8)$ & $0(0)$ & $31(58.4)$ & - \\
\hline \multicolumn{5}{|l|}{ Medication in $\mathrm{BP}^{\mathrm{g}}$} \\
\hline - Flecainide $(n, \%)$ & $62(29.6)$ & $42(26.9)$ & $20(37.7)$ & 0.122 \\
\hline - Propafenone $(n, \%)$ & $2(0.95)$ & $1(0.64)$ & $1(1.8)$ & 0.415 \\
\hline - Amiodarone (n, \%) & $9(4.3)$ & $6(3.8)$ & $3(5.6)$ & 0.561 \\
\hline - Sotalol $(n, \%)$ & $49(23.4)$ & $34(21.8)$ & $15(28.3)$ & 0.310 \\
\hline - Metoprolol (n, \%) & $1(0.4)$ & $1(0.6)$ & $0(0)$ & 0.562 \\
\hline - Bisoprolol $(n, \%)$ & $111(53.11)$ & $81(51.9)$ & $30(56.6)$ & 0.497 \\
\hline - Nebivolol $(n, \%)$ & $4(1.9)$ & $4(2.5)$ & $0(0)$ & 0.241 \\
\hline - ACE inhibitors $(n, \%)$ & $27(12.9)$ & $21(13.4)$ & $6(11.3)$ & 0.710 \\
\hline$-\operatorname{ARBs}(n, \%)$ & $6(2.8)$ & 6 & 0 & 0.150 \\
\hline \multicolumn{5}{|l|}{ Medication after BP } \\
\hline - Flecainide (n, \%) & $25(11.9)$ & $17(10.8)$ & $8(15)$ & 0.398 \\
\hline - Propafenone $(n, \%)$ & $2(0.9)$ & $0(0)$ & $2(3.7)$ & 0.060 \\
\hline - Amiodarone (n, \%) & $6(2.8)$ & $3(1.9)$ & $3(5.6)$ & 0.154 \\
\hline
\end{tabular}


Table 1 Baseline clinical and demographic characteristics (Continued)

\begin{tabular}{|c|c|c|c|c|}
\hline Characteristic & Study population $(n=209)$ & AF recurrence $-(n=156)$ & AF recurrence $+(n=53)$ & $P$ value \\
\hline - Sotalol $(n, \%)$ & $26(12.4)$ & $18(11.5)$ & $8(15)$ & 0.478 \\
\hline - Metoprolol (n, \%) & $1(0.4)$ & $1(0.6)$ & $0(0)$ & 0.562 \\
\hline - Bisoprolol $(n, \%)$ & $62(29.6)$ & $50(23.9)$ & $12(22.6)$ & 0.211 \\
\hline - Nebivolol $(n, \%)$ & $6(2.8)$ & $5(3.2)$ & $1(1.8)$ & 0.628 \\
\hline - ACE inhibitors $(n, \%)$ & $27(12.9)$ & $21(13.4)$ & $6(11.3)$ & 0.710 \\
\hline - ARBs $(n, \%)$ & $6(2.8)$ & 6 & 0 & 0.150 \\
\hline Recurrence in $\mathrm{BP}$ & $8(3.8)$ & $0(0)$ & $8(15.1)$ & $<0.001$ \\
\hline
\end{tabular}

${ }^{\mathrm{a}}$ TIA Transient ischaemic attack, ${ }^{\mathrm{b}} C V A$ Cerebrovascular accident, ${ }^{\mathrm{c}} A C E$ inhibitors, angiontensin - converter enzyme inhibitors, ${ }^{\mathrm{d}} A R B s$ angiotensin receptor blockers, ${ }^{\mathrm{e}} A V N R T$ atrioventricular nodal reentry tachycardia, ${ }^{\mathrm{f}} A F$ atrial fibrillation, ${ }^{\mathrm{g}} B P$ blanking period

monitoring was performed if arrhythmic symptoms occurred. All documented AF episodes $>30$ s were considered as a recurrence. A BP of 3 months was considered for the study.

\section{Statistical analysis}

Continuous variables are expressed as mean \pm standard deviation. Categorical variables are expressed as percentages. Comparisons of continuous variables were done with a Student t-test or Mann-Whitney U-test and binomial variables with a chi-square or Fisher test as appropriate. Receiver-operator characteristic (ROC) curves were constructed to evaluate the performance of variables in predicting $\mathrm{AF}$ recurrence and to calculate adjusted cut-off values, specificity and sensitivity of the parameters (using Youden's Index) in the prediction of AF recurrence. Freedom from AF recurrence was estimated by Kaplan-Meier method and time-dependent comparisons by the log-rank test. In order to evaluate potential predictors of AF recurrence, a separate Cox proportional hazard model was used. Intraclass correlation coefficient (ICC) was used to determine the intraand inter - observer variability. The calculated ICCs were judged as follows: 0.50 to 0.74 poor to moderate, 0.75 to 0.92 good and $>0.93$ excellent. Statistical significance was considered with a $P$-value $<0.05$. Statistical analyses were conducted using IBM SPSS Statistic for Windows, Version 24.0 (Armonk, NY: IBM Corp.)
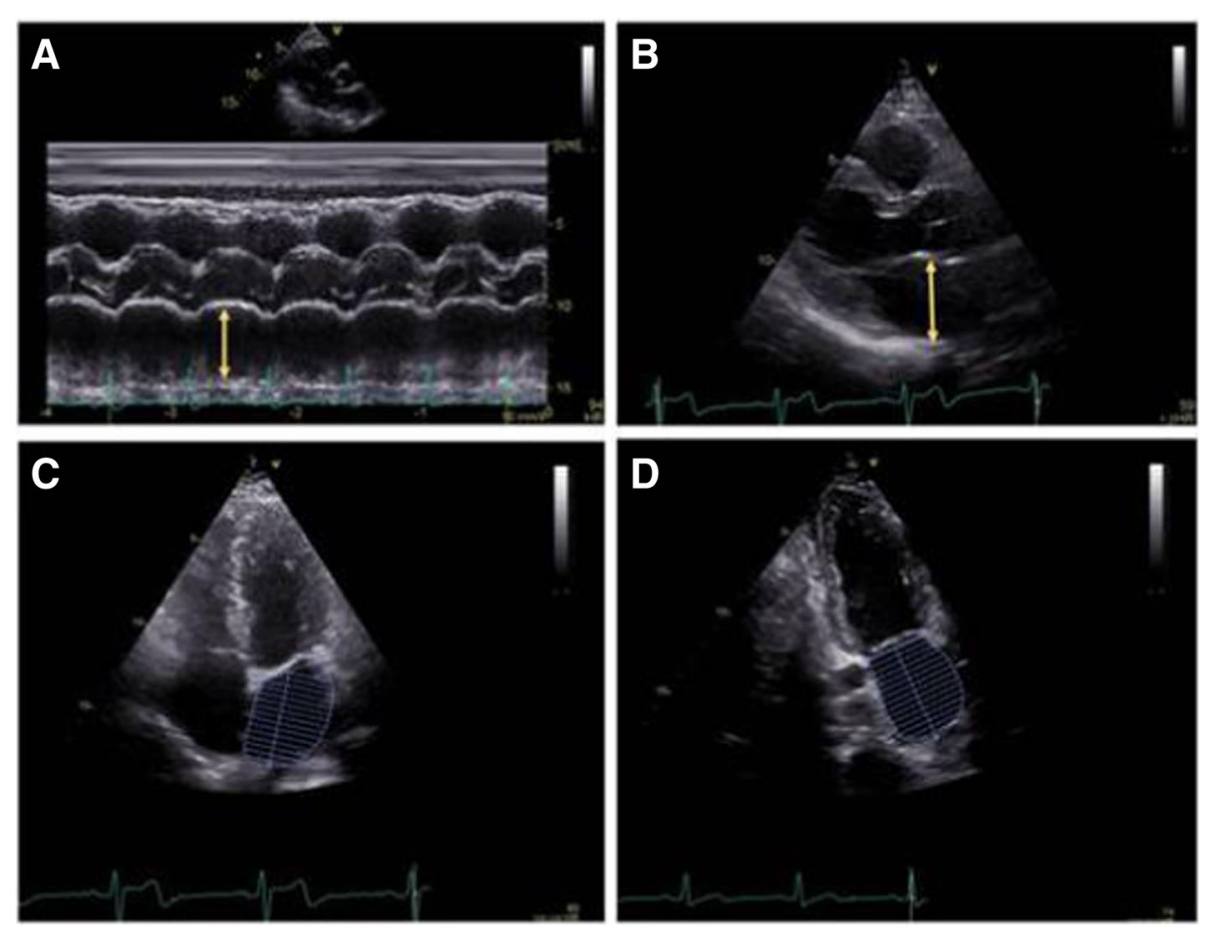

Fig. 1 a. Illustration of the left atrium anterior - posterior diameter measurement in M-Mode, using the parasternal long axis view. b. Left atrium anterior - posterior diameter measurement in 2D parasternal long axis view. c. Left atrium volume measurement in four - chamber view. $\mathbf{d}$. Left atrium volume measurement in two - chamber view 

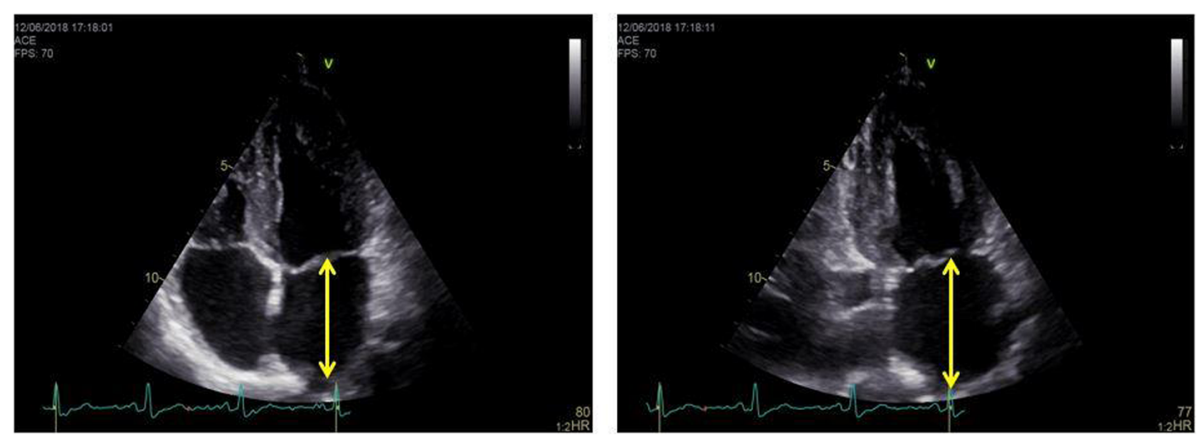

Fig. 2 Left atrium length (superior - inferior diameter) is measured perpendicular from the mid-point of the segment that unifies the hinge points of the mitral leaflets to the roof of the left atrium

\section{Results}

At a mean follow - up of $16.8 \pm 6.3$ months after the BP, $53(25.4 \%)$ patients presented recurrences of AF.

\section{Baseline population characteristics and recurrences}

Baseline clinical and demographic characteristics of the study population are listed in Table 1 . There was a significant difference between the groups with and without recurrence for patients who presented early AF recurrence.

Echocardiographic characteristics are presented in Table 2. In brief, there was a significant difference in patients with and without recurrence respectively for LV end-diastolic diameter $(50.3 \pm 7.9 \mathrm{~mm}$ vs. $47.2 \pm 6.5 \mathrm{~mm}$, $p=0.013)$, LV mass index $\left(83.7 \pm 28.4 \mathrm{~g} / \mathrm{m}^{2}\right.$ vs. $76.6 \pm$ $\left.26.3 \mathrm{~g} / \mathrm{m}^{2}, p=0.045\right)$, LAD $(42.2 \pm 7.2 \mathrm{~mm}$ vs. $39 \pm$ $6.1 \mathrm{~mm}, p=0.013)$, LAmax $(67.3 \pm 27.8 \mathrm{~mL}$ vs. $57.7 \pm$ $21.2 \mathrm{~mL}, p=0.036)$, LAmin $(36.7 \pm 20.1 \mathrm{~mL}$ vs. $27.5 \pm$ $14.9 \mathrm{~mL}, p=0.004)$ and LAmin indexed $(18.1 \pm 9.3 \mathrm{~mL} /$ $\mathrm{m}^{2}$ vs. $\left.14.1 \pm 7.4 \mathrm{~mL} / \mathrm{m}^{2}, p=0.007\right)$.

\section{Procedural data}

All the patients underwent the procedure with the large 28-mm CBA. At the beginning of the procedure, 203 (97.1\%) patients were in sinus rhythm. The mean total procedure and fluoroscopy time were $66.9 \pm 20.2 \mathrm{~min}$, respectively $13.8 \pm 7.5 \mathrm{~min}$. The mean number of freeze-thaw cycles was $1.2 \pm 0.4$ in the LSPV, $1.1 \pm 0.3$ in the LIPV, $1.19 \pm 0.44$ in the RSPV, $1.2 \pm 0.5$ in the RIPV. The mean minimal temperatures obtained were $-48.7 \pm$ $8.6{ }^{\circ} \mathrm{C}$ in LSPV, $-48.7 \pm 8.6$ in LIPV, $-49.2 \pm 10.8$ in RSPV, $-46 \pm 14.6$ in RIPV. There were no significant differences regarding the procedural data between the two groups. Procedural data can be found in Table 3 .

\section{Global versus longitudinal LA remodeling and AF recurrences}

Fig. 3 illustrates that using only the LAD, with an adjusted cut-off value of $41 \mathrm{~mm}$, led missing up to $30.2 \%$ of AF recurrences. In the patients with recurrence without LAD dilation, a significant number of patients had longitudinal LA remodeling (increased superior - inferior LA diameter, with an adjusted cut-off value of $41 \mathrm{~mm})$.

\section{LA volumes and AF recurrences}

Multivariate regression analysis showed that LAD, LAmin and early AF recurrence were independent predictors of AF recurrence after the BP, as illustrated in Table 4.

ROC analysis revealed that for a cut-off value of $23.69 \mathrm{ml}$ for LAmin it was associated with a high sensitivity for predicting AF recurrence after the BP $(79.5 \%$ sensitivity, $46 \%$ specificity). For the above mentioned adjusted cut-off values, LAmin had a high negative predictive values for AF recurrences 87.3\% .

In contrast, for LAD, sensitivity and specificity were $56.3 \%$ and $66 \%$, respectively, with a lower negative predictive value of $73 \%$ compared to LAmin.

\section{Reproducibility}

Intraobserver variability was excellent for all the parameters. For LAD the ICC was 0.972, for LA superior - inferior diameter $\mathrm{ICC}=0.95$, for LAmax $\mathrm{ICC}=0.964$ and for LAmin $\mathrm{ICC}=0.940$. Interobserver reliability was good for LAD (ICC =0.906), LAmax $(\mathrm{ICC}=0.907)$ and LAmin (0.860) and excellent for LA superior - inferior diameter $(\mathrm{ICC}=0.96)$.

\section{Discussion}

The main findings of our study are: 1) recurrence of AF after the BP occurred in $25.4 \%$ of all subjects with paroxysmal AF. 2) In the group of patients with AF recurrence, longitudinal remodeling (increased superior inferior LA diameter) was also present in patients with normal LAD. 3) In the global population of patients undergoing CBA, LA minimum volume was an independent predictor of AF recurrences after the BP. These 
Table 2 Echocardiographic parameters

\begin{tabular}{|c|c|c|c|c|}
\hline Characteristic & Study population $(n=209)$ & AF recurrence $-(n=156)$ & AF recurrence $+(n=53)$ & $P$ value \\
\hline Heart rate during echocardiography & $75.6 \pm 14.5$ & $76.3 \pm 14.1$ & $75.6 \pm 14.5$ & 0.080 \\
\hline \multicolumn{5}{|l|}{ Left ventricle } \\
\hline - LVEF ${ }^{\mathrm{a}}, \%$ & $54.4 \pm 5.2$ & $54.6 \pm 4.7$ & $53.8 \pm 6.4$ & 0.343 \\
\hline$-\mathrm{LV}^{\mathrm{b}} E D D^{c}, \mathrm{~mm}$ & $48 \pm 7$ & $47.2 \pm 6.5$ & $50.3 \pm 7.9$ & 0.013 \\
\hline - LVESD ${ }^{d}, \mathrm{~mm}$ & $30.4 \pm 5.8$ & $30.4 \pm 5.9$ & $30.5 \pm 5.7$ & 0.939 \\
\hline$-\mathrm{IVS}_{d}{ }^{\mathrm{e}}, \mathrm{mm}$ & $9.5 \pm 1.7$ & $9.5 \pm 1.78$ & $9.6 \pm 1.7$ & 0.763 \\
\hline$-P W_{d}^{f}, m m$ & $9.3 \pm 1.6$ & $9.1 \pm 1.4$ & $9.6 \pm 1.8$ & 0.131 \\
\hline - LV mass, g & $140.4 \pm 72.8$ & $136.8 \pm 70.1$ & $150.9 \pm 80$ & 0.073 \\
\hline - LV mass index, $\mathrm{g} / \mathrm{m}^{2}$ & $78.4 \pm 26.9$ & $76.6 \pm 26.3$ & $83.7 \pm 28.4$ & 0.045 \\
\hline - LV EDV ${ }^{9}, \mathrm{~mL}$ & $99 \pm 32.5$ & $96.4 \pm 30.5$ & $109.8 \pm 39.6$ & 0.223 \\
\hline - LV ESVh, mL & $46.8 \pm 20.8$ & $45.4 \pm 20.6$ & $52.4 \pm 21.6$ & 0.196 \\
\hline \multicolumn{5}{|l|}{ Left atrium } \\
\hline - LA' antero-posterior diameter, $\mathrm{mm}$ & $39.8 \pm 6.5$ & $39 \pm 6.1$ & $42.2 \pm 7.2$ & 0.013 \\
\hline - LA antero-posterior diameter indexed, $\mathrm{mm} / \mathrm{m}^{2}$ & $20.4 \pm 3.4$ & $20.1 \pm 3.3$ & $20.4 \pm 3.4$ & 0.182 \\
\hline - LA superior- inferior diameter, $\mathrm{mm}$ & $48.8 \pm 7.6$ & $48.3 \pm 7.6$ & $50.3 \pm 7.4$ & 0.095 \\
\hline - LA maximum volume, $\mathrm{mL}$ & $60 \pm 23.3$ & $57.7 \pm 21.2$ & $67.3 \pm 27.8$ & 0.036 \\
\hline - LA maximum volume indexed, $\mathrm{ml} / \mathrm{m}^{2}$ & $30.4 \pm 10.8$ & $29.5 \pm 10$ & $33.5 \pm 12.6$ & 0.067 \\
\hline - LA minimum volume, $\mathrm{mL}$ & $29.8 \pm 16.8$ & $27.5 \pm 14.9$ & $36.7 \pm 20.1$ & 0.004 \\
\hline - LA minimum volume indexed, $\mathrm{mL} / \mathrm{m}^{2}$ & $15.1 \pm 8$ & $14.1 \pm 7.4$ & $18.1 \pm 9.3$ & 0.007 \\
\hline \multicolumn{5}{|l|}{ Doppler } \\
\hline - E- wave velocity, $\mathrm{m} / \mathrm{s}$ & $0.6 \pm 0.1$ & $0.6 \pm 0.1$ & $0.6 \pm 0.1$ & 0.768 \\
\hline - A - wave velocity, $\mathrm{m} / \mathrm{s}$ & $0.5 \pm 0.1$ & $0.5 \pm 0.1$ & $0.4 \pm 0.1$ & 0.405 \\
\hline - E/A (ratio) & $1.4 \pm 0.5$ & $1.3 \pm 0.5$ & $1.4 \pm 0.5$ & 0.314 \\
\hline - DTE, ms & $180.8 \pm 44.4$ & $180.2 \pm 45.4$ & $182.7 \pm 41.6$ & 0.482 \\
\hline - TDI $\mathrm{e}^{\prime}$ septal, cm/s & $7.4 \pm 2.1$ & $7.3 \pm 2$ & $7.8 \pm 2.5$ & 0.366 \\
\hline - TDI e' lateral,cm/s & $9.4 \pm 4.9$ & $9.6 \pm 5.3$ & $9 \pm 2.8$ & 0.965 \\
\hline - E/e' avg. (ratio) & $8.6 \pm 2.9$ & $8.7 \pm 2.9$ & $8.4 \pm 3.2$ & 0.893 \\
\hline - TDI a' septal, cm/s & $7.4 \pm 2$ & $7.6 \pm 2$ & $6.8 \pm 2$ & 0.053 \\
\hline - TDI a' lateral, cm/s & $8 \pm 2.4$ & $8.1 \pm 2.4$ & $7.5 \pm 2.4$ & 0.111 \\
\hline Mitral regurgitation $(n, \%)$ & $97(46.4)$ & $70(44.8)$ & $27(50.9)$ & 0.594 \\
\hline - Mild $(n, \%)$ & $90(43.1)$ & $64(41)$ & $26(49.1)$ & \\
\hline - Moderate $(n, \%)$ & $7(3.3)$ & $6(3.8)$ & $1(1.9)$ & \\
\hline Mitral annulus calcification $(n, \%)$ & $10(4.8)$ & $7(4.5)$ & $3(5.7)$ & 0.677 \\
\hline Aortic regurgitation (mild) $(n, \%)$ & $24(11.9)$ & $20(12.8)$ & $4(7.5)$ & 0.298 \\
\hline Tricupid regurgitation ( $n, \%)$ & $106(50.7)$ & $77(49.3)$ & $29(54.7)$ & 0.338 \\
\hline - Mild ( $n, \%)$ & $96(45.9)$ & $70(44.8)$ & $26(49)$ & \\
\hline - Moderate $(n, \%)$ & $9(4.3)$ & $7(4.4)$ & $2(3.7)$ & \\
\hline - Severe $(n, \%)$ & $1(0.4)$ & $0(0)$ & $1(1.8)$ & \\
\hline TAPSE', mm & $23.1 \pm 4$ & $23 \pm 3.7$ & $23.5 \pm 4.9$ & 0.253 \\
\hline $\mathrm{IVC}^{\mathrm{m}}, \mathrm{mm}$ & $14.3 \pm 4$ & $14.1 \pm 3.9$ & $15.1 \pm 4.2$ & 0.258 \\
\hline $\mathrm{TR}^{\mathrm{n}}$ gradient, $\mathrm{mmHg}$ & $24.9 \pm 7.5$ & $25.1 \pm 7.7$ & $24.1 \pm 6.9$ & 0.783 \\
\hline
\end{tabular}

${ }^{\mathrm{a}} \mathrm{LVEF}$ left ventricle ejection fraction, ${ }^{\mathrm{b}} \mathrm{L} V$ left ventricle, ${ }^{\mathrm{C}} E D D$ end - diastolic diameter, ${ }^{\mathrm{d}} E S D$ end - systolic diameter, ${ }^{\mathrm{e}} / V S d$ Interventricular septum end-diastolic diameter, ${ }^{\mathrm{f}} P W d$ posterior wall end-diastolic diameter, ${ }^{9} E D V$ end - diastolic volume, ${ }^{\mathrm{h}} E S V$ end - systolic volume, ${ }^{\mathrm{i}} \mathrm{L}$ ( left atrium, ${ }^{\mathrm{j}} \mathrm{DTE}$ deceleration time of $\mathrm{E}-$ wave, ${ }^{\mathrm{k}} T D I$, tissue Doppler imaging, 'TAPSE tricuspid annulus plane systolic excursion, ${ }^{\mathrm{m}} / V C$ inferior vena cava, ${ }^{\mathrm{n}} T R$ tricuspid regurgitation 
Table 3 Procedural data

\begin{tabular}{|c|c|c|c|c|}
\hline Characteristic & Study population $(n=209)$ & AF recurrence $-(n=156)$ & AF recurrence $+(n=53)$ & $P$ value \\
\hline Procedural time, $\min$ & $66.9 \pm 20.2$ & $67 \pm 20.3$ & $66.5 \pm 19.9$ & 0.918 \\
\hline Fluoroscopy time, min & $13.8 \pm 7.5$ & $13.4 \pm 7.2$ & $14.7 \pm 8.3$ & 0.452 \\
\hline Freezes in LSPV ${ }^{a}$ & $1.2 \pm 0.4$ & $1.2 \pm 0.4$ & $1.2 \pm 0.4$ & 0.656 \\
\hline Freezes in LIPV & $1.1 \pm 0.3$ & $1.1 \pm 0.4$ & $1.1 \pm 0.3$ & 0.215 \\
\hline Freezes in RSPV & $1.1 \pm 0.4$ & $1.1 \pm 0.4$ & $1.2 \pm 0.4$ & 0.086 \\
\hline Freezes in RIPV & $1.2 \pm 0.5$ & $1.2 \pm 0.4$ & $1.2 \pm 0.5$ & 0.366 \\
\hline LSPV freeze duration, $\mathrm{s}$ & $223.6 \pm 78.9$ & $224.8 \pm 80.5$ & $220 \pm 74.6$ & 0.782 \\
\hline LIPV freeze duration, s & $208.2 \pm 65.5$ & $211.1 \pm 69$ & $199.7 \pm 53.7$ & 0.412 \\
\hline RSPV freeze duration, $\mathrm{s}$ & $208.5 \pm 79$ & $206 \pm 75$ & $215.9 \pm 89.8$ & 0.647 \\
\hline RIPV freeze duration, $s$ & $225.4 \pm 89.1$ & $223 \pm 89.4$ & $232.5 \pm 88.8$ & 0.147 \\
\hline Min temp in $L S P V,{ }^{\circ} \mathrm{C}$ & $-48.7 \pm 8.6$ & $-48.7 \pm 9.5$ & $-48.6 \pm 5$ & 0.325 \\
\hline Min temp in LIPV, ${ }^{\circ} \mathrm{C}$ & $-45.4 \pm 8.6$ & $-45.5 \pm 9.5$ & $-44.9 \pm 5.4$ & 0.192 \\
\hline Min temp in $\mathrm{RSPV},{ }^{\circ} \mathrm{C}$ & $-49.2 \pm 10.8$ & $-49.3 \pm 11.9$ & $-47 \pm 14.6$ & 0.246 \\
\hline Min temp in $\mathrm{RIPV},{ }^{\circ} \mathrm{C}$ & $-46 \pm 14.6$ & $-45.4 \pm 16.3$ & $-47.9 \pm 6.5$ & 0.698 \\
\hline Pulmonary veins variants & $102(48.8)$ & $79(50.6)$ & $23(43.3)$ & 0.347 \\
\hline - Left common ostium & $58(27.8)$ & $42(26.9)$ & $16(30.2)$ & 0.647 \\
\hline - Right middle pulmonary vein & $29(13.9)$ & $25(16.0)$ & $4(7.5)$ & 0.124 \\
\hline - Right common ostium & $8(3.8)$ & $7(4.5)$ & $1(1.9)$ & 0.640 \\
\hline - Other & $7(3.3)$ & $5(3.2)$ & $2(3.8)$ & 0.686 \\
\hline
\end{tabular}

${ }^{\mathrm{a}} L S P V$ left superior pulmonary vein, ${ }^{\mathrm{b}}$ LIPV left inferior pulmonary vein, ${ }^{\mathrm{c}} R S P V$ right superior pulmonary vein, ${ }^{\mathrm{d}} R I P V$ right inferior pulmonary vein, ${ }^{\mathrm{e}}$ Min temp, minimum temperature

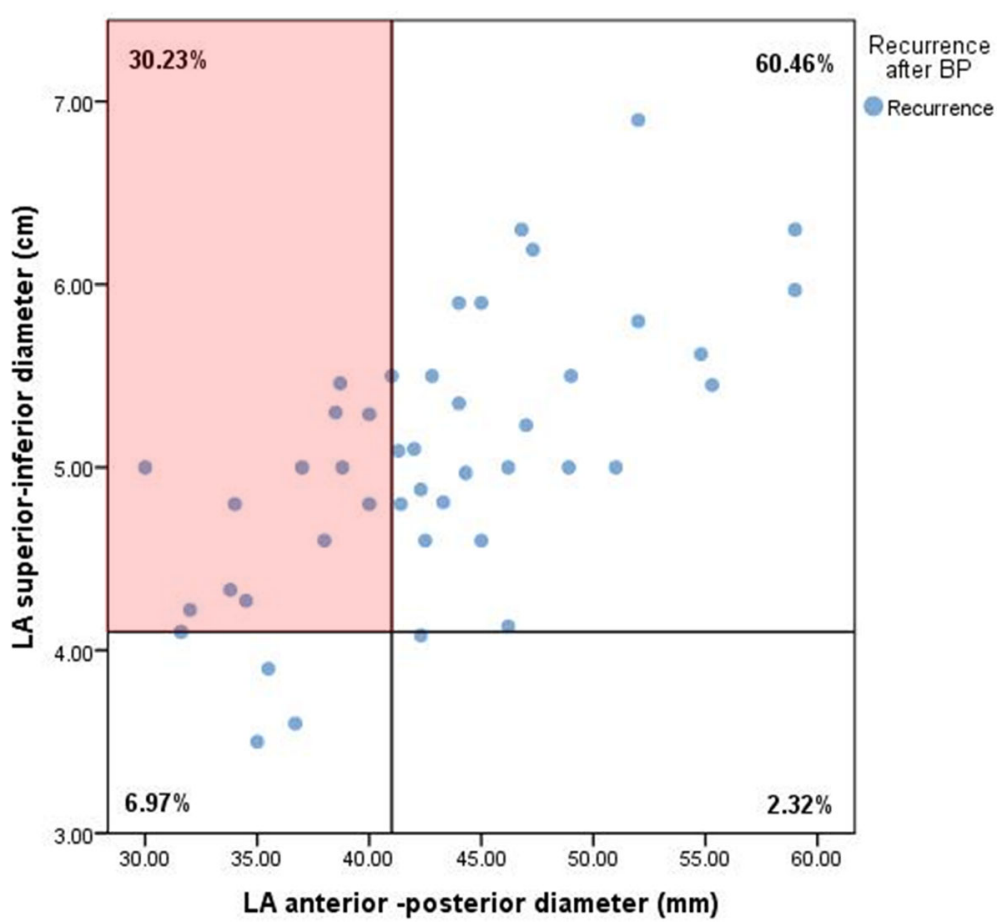

Fig. 3 Proportions of patients with AF recurrences according to the adjusted cut - off values for LA superior - inferior diameter (41 mm) and LA anterior - posterior diameter $(41 \mathrm{~mm})$, showing that $30.2 \%$ of patients with recurrence had longitudinal remodeling, in the absence of an increased anterior-posterior diameter 
Table 4 Predictors of atrial fibrillation recurrence

\begin{tabular}{|c|c|c|c|c|c|c|c|c|}
\hline \multirow[t]{3}{*}{ Parameters } & \multirow{2}{*}{\multicolumn{2}{|c|}{ Univariate analysis }} & \multicolumn{6}{|l|}{ Multivariate analysis } \\
\hline & & & \multicolumn{2}{|l|}{ Model 1} & \multicolumn{2}{|l|}{ Model 2} & \multicolumn{2}{|l|}{ Model 3} \\
\hline & $\mathrm{HR}^{\mathrm{h}}\left(95 \% \mathrm{Cl}^{\mathrm{i}}\right)$ & $p$ & HR $(95 \% \mathrm{Cl})$ & $p$ & HR $(95 \%$ Cl) & $p$ & HR (95\% Cl) & $p$ \\
\hline$\overline{\mathrm{AHT}^{\mathrm{a}}}$ & $1.608(0.937-2.762)$ & 0.085 & $1.675(0.886-3.166)$ & 0.112 & $1.489(0.771-2.875)$ & 0.236 & $1.433(0.773-2.658)$ & 0.254 \\
\hline $\mathrm{DM}^{\mathrm{b}}$ & $2.141(0.963-4.763)$ & 0.062 & $1.447(0.549-3.816)$ & 0.455 & $1.410(0.541-3.679)$ & 0.482 & $1.389(0.523-3.688)$ & 0.509 \\
\hline Recurrence in $\mathrm{BP}^{\mathrm{C}}$ & $4.867(2.174-10.892)$ & $<0.001^{*}$ & $4.457(1.647-12.062)$ & $0.003^{*}$ & $4.990(1.884-13.215)$ & $0.001^{*}$ & 4.504 (1.830-11.088) & $0.001^{*}$ \\
\hline LVd mass index & $1.010(0.998-1.022)$ & 0.100 & $1.008(0.993-1.023)$ & 0.301 & $1.007(0.992-1.021)$ & 0.366 & $1.003(0.990-1.015)$ & 0.681 \\
\hline$\angle A D^{e}$ & $1.017(1.006-1.028)$ & $0.003^{*}$ & $1.062(1.010-1.117)$ & $0.018^{*}$ & & & & \\
\hline $\operatorname{LAmax}^{f}$ & $1.024(1.011-1.036)$ & $<0.001^{*}$ & & & $1.009(0.996-1.022)$ & 0.157 & & \\
\hline LAmin $^{9}$ & $1.078(1.031-1.127)$ & $0.001^{*}$ & & & & & $1.016(1.001-1.031)$ & $0.039^{*}$ \\
\hline
\end{tabular}

${ }^{\mathrm{a}} A H T$ arterial hypertension, ${ }^{\mathrm{b}} D M$ diabetes mellitus, ${ }^{\mathrm{c}} B P$ blanking period, ${ }^{\mathrm{d}} L V$ left ventricle, ${ }^{\mathrm{e}} L A D$ left atrium diameter, ${ }^{\mathrm{f}} L A m a x$ left atirum maximum volume, ${ }^{\mathrm{g}} L A m i n$ left atrium minimum volume, ${ }^{\mathrm{h}} H R$ hazard ratio; ${ }^{\mathrm{i}} \mathrm{Cl}$ confidence interval, ${ }^{*} p<0.05$

results suggest that AF recurrence after ablation also occurs in the absence of global LA remodeling assessed by LAD.

This study evaluates the role of additional anatomical parameters of the LA using two-dimensional echocardiography for the prediction of recurrence of AF after the $\mathrm{BP}$ in patients who have undergone $\mathrm{CBA}$.

The incidence of recurrence of AF after the $\mathrm{BP}$ in our study was of $25.4 \%$, which is consistent with results of previous studies. Gerede et al. [6] have reported a rate of recurrence after the $\mathrm{BP}$ of $31.3 \%$. In a recent study published by Coutino et al. [5] they showed a rate of recurrence after the BP of $25.2 \%$. Previous studies have shown that the presence of recurrence during the $\mathrm{BP}$ is an independent predictor of late $\mathrm{AF}$ recurrence, which was also confirmed by our analysis $[14,15]$.

Previous studies have shown that the enlargement of $\mathrm{LAD}$ is an independent predictor of recurrence of $\mathrm{AF}$ after the BP, suggesting that the remodeling of the LA is a leading cause for late recurrences of $\operatorname{AF}[4,6]$. This is consistent with our results that report LAD as a predictor of recurrence of AF after CBA.

However, the remodeling of the LA can occur non-uniformly, correlating with reduced success of different ablation techniques $[9,16]$ and furthermore, LAD is not considered as representative of LA dimension following the EACVI/ASE recommendations $[10,11]$. Our study shows that $30.2 \%$ of the patients with a normal LAD, but a dilated superior - inferior diameter presented AF recurrence after the BP. This novel finding suggests that longitudinal remodeling is also involved in AF recurrence after ablation. However, longitudinal LA dilation could also be observed in patients without recurrence and was not significantly predictive for AF recurrence. These data shows that LA remodeling is a spatial process.

Therefore, LA volumes assessment may be a more discriminative parameter of remodeling to predict $\mathrm{AF}$ recurrence.
Interestingly, our study showed that LAmin was an independent predictors of AF recurrence after the BP, and that it was associated with a high sensitivity for predicting recurrence for the adjusted cut-off values (79.5\%).

Limited data is available regarding the value of LA minimum volume and its prognostic value for different cardiovascular events. LAmin volume was associated with the occurrence of AF in an elderly cohort, as showed by Fatema et al. [17] and it was the most accurate parameter reflecting anatomical remodeling associated with paroxysmal AF in a recent study performed by Schaaf et al. [7]. In several studies, LA minimum volume was associated with diastolic dysfunction starting from incipient stages $[18,19]$. However, we did not find a significant difference regarding the diastolic function between the groups with and without recurrence. These findings suggest that LA minimum volume represents a more subtle form of LA remodeling that could also trigger the occurrence of AF recurrence after ablation.

Whether LA minimum volume may have a better prognostic value in predicting late AF recurrences following cryoballoon ablation requires further investigations.

As suggested by Canpolat et al. [20], CBA may have a positive impact on LA reverse remodeling. Since the remodeling is a continuous process, measurements performed at a single moment may not reflect the truth and a temporal trend of the LA volumes should be assessed. However, data regarding LA reverse remodeling is limited and there are no clear definitions for it, therefore it should be evaluated in further studies.

\section{Study limitations}

This is a single center retrospective study, therefore results may not be generalized. Larger prospective clinical studies are warranted to confirm our findings. Moreover, the present study addressed the prognostic value of LA anatomy only in paroxysmal AF and cannot be extrapolated to a persistent $\mathrm{AF}$ population undergoing $\mathrm{CBA}$. 


\section{Future perspectives}

As mentioned earlier, it is widely accepted that anatomical remodeling is associated with recurrence of $\mathrm{AF}$ after ablation [4, 6, 9, 16, 21, 22]. 2D echocardiography can provide useful information for the detection of patients at risk to develop recurrences of AF, but LA volumes are still based on only two orthogonal planes and related to geometrical assumptions. Our results suggest that LA longitudinal remodeling could play an additional role in the prediction of AF recurrences, as the expansion of the LA can be asymmetrical. Therefore, advanced imaging techniques such as three - dimensional (3D) echocardiography can overcome these limitations and provide more accurate and reproducible LA measurements [23]. Moreover, several studies showed that LA strain could predict recurrence of AF after catheter ablation. Therefore, strain imaging may bring additional information regarding the more subtle structural and functional left atrium remodeling in such patients and could be used for the follow-up assessment of possible reverse atrial remodeling [24-26].

\section{Conclusions}

The results of our study showed that LA longitudinal remodeling, assessed by the increase of LA superior - inferior diameter plays an additional role in AF recurrence after CBA. Moreover, LA minimum volume was an independent predictors of AF recurrences after the BP, suggesting that less advanced forms of LA remodeling, not detected by the dilation of LAD can trigger AF recurrences. Further large - scale prospective randomized studies are needed to confirm our results.

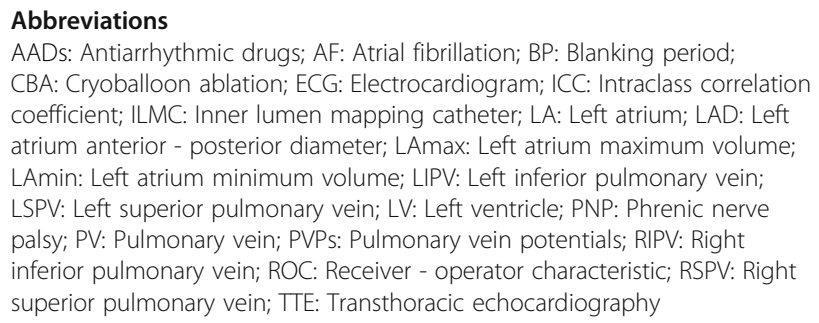

Abbreviations

AADs: Antiarrhythmic drugs; AF: Atrial fibrillation; BP: Blanking period; CBA: Cryoballoon ablation; ECG: Electrocardiogram; ICC: Intraclass correlation coefficient; ILMC: Inner lumen mapping catheter; LA: Left atrium; LAD: Left atrium anterior - posterior diameter; LAmax: Left atrium maximum volume; LAmin: Left atrium minimum volume; LIPV: Left inferior pulmonary vein; LSPV: Left superior pulmonary vein; LV: Left ventricle; PNP: Phrenic nerve palsy; PV: Pulmonary vein; PVPs: Pulmonary vein potentials; RIPV: Right inferior pulmonary vein; ROC: Receiver - operator characteristic; RSPV: Right superior pulmonary vein; TTE: Transthoracic echocardiography

\section{Funding}

Andreea Motoc received a grant from Centrum Voor Hart - en Vaatziekten as fellow in cardiac imaging.

Juan - Pablo Abugattas received a grant from Centrum Voor Hart - en Vaatziekten as postgraduate fellow in cardiac electrophysiology and pacing. Gian - Battista Chierchia received compensation for teaching purposes and proctoring from AF solutions, Medtronic.

Carlo de Asmundis received compensation for teaching purposes and proctoring from AF solutions, Medtronic and research grants on behalf of the Heart Rhythm Management center from Biotronik, Medtronic, St Jude Medical - Abbot, Livanova, Boston Scientific, Biosense Webster.

\section{Availability of data and materials}

The datasets used and analyzed during the current study are available from the corresponding author on reasonable request.

\section{Authors' contributions}

All authors contributed equally in analyzing and interpreting the patients' data and writing the manuscript. All authors read and approved the final manuscript.

\section{Ethics approval and consent to participate}

The study was approved by the local Ethical Committee and was carried out in accordance with the ethical principles for medical research involving human subjects established by Helsinki's Declaration, protecting the privacy of all participants, as well as the confidentiality of their personal information. All patients provided written informed consents.

\section{Consent for publication}

Not applicable.

\section{Competing interests}

The authors declare that they have no competing interests.

\section{Publisher's Note}

Springer Nature remains neutral with regard to jurisdictional claims in published maps and institutional affiliations.

\section{Author details}

${ }^{1}$ Centrum Voor Hart-en Vaatziekten (CHVZ), Department of Cardiology, UZ Brussel, Laarbeeklaan 101, 1090 Brussels, Belgium. ${ }^{2}$ Heart Rhythm Management Centre, UZ Brussel, Laarbeeklaan 101, 1090 Brussels, Belgium.

Received: 17 May 2018 Accepted: 3 August 2018

Published online: 25 September 2018

\section{References}

1. Kirchhof $P$, et al. 2016 ESC guidelines for the management of atrial fibrillation developed in collaboration with EACTS. Eur Heart J. 2016;37(38): 2893-962.

2. Chen C-F, Gao X-F, Duan X, Chen B, Liu X-H, Xu Y-Z. Comparison of catheter ablation for paroxysmal atrial fibrillation between cryoballoon and radiofrequency: a meta-analysis. J Interv Card Electrophysiol. 2017:48(3):35166.

3. Garg J, et al. Cryoballoon versus Radiofrequency Ablation for Atrial Fibrillation: A Meta-analysis of 16 Clinical Trials. J Atr Fibrillation. 2016;9(3): 1429.

4. Aytemir K, et al. Safety and efficacy outcomes in patients undergoing pulmonary vein isolation with second-generation cryoballoondagger. Eur Eur pacing, arrhythmias, Card Electrophysiol J Work groups Card pacing, arrhythmias, Card Cell Electrophysiol Eur Soc Cardiol. 2015;17(3):379-87.

5. Coutiño $\mathrm{H}-\mathrm{E}$, et al. Role of the burden of premature atrial contractions during the blanking period following second-generation cryoballoon ablation in predicting late recurrences of atrial arrhythmias. J Interv Card Electrophysiol. 2017;49(3):329-35.

6. Gerede DM, et al. Prediction of recurrence after cryoballoon ablation therapy in patients with paroxysmal atrial fibrillation. Anatol J Cardiol. 2015; 16(7):482-88.

7. Schaaf $M$, et al. Left atrial remodelling assessed by $2 \mathrm{D}$ and $3 \mathrm{D}$ echocardiography identifies paroxysmal atrial fibrillation. Eur Heart J Cardiovasc Imaging. 2017;18(1):46-53.

8. Badano LP, et al. How many patients would be misclassified using M-mode and two-dimensional estimates of left atrial size instead of left atrial volume? A three-dimensional echocardiographic study. J Cardiovasc Med (Hagerstown). 2008;9(5):476-84

9. Nedios $\mathrm{S}$, et al. Comparison of left atrial dimensions in $\mathrm{CT}$ and echocardiography as predictors of long-term success after catheter ablation of atrial fibrillation. J Interv Card Electrophysiol. 2015;43(3):237-44.

10. Lancellotti P, Zamorano JL, Habib G, Badano L. The EACVI Textbook of Echocardiography. Oxford: Oxford University Press; 2016.

11. Lang RM, et al. Recommendations for cardiac chamber quantification by echocardiography in adults: an update from the American Society of Echocardiography and the European Association of Cardiovascular Imaging. Eur Heart J Cardiovasc Imaging. 2015;16(3):233-70.

12. Nagueh SF, et al. Recommendations for the evaluation of left ventricular diastolic function by echocardiography: an update from the American Society of Echocardiography and the European Association of 
Cardiovascular Imaging. Eur Heart J Cardiovasc Imaging. 2016;17(12):132160.

13. De Regibus $V$, et al. Single freeze strategy with the second- generation cryballoon for atrial fibrillation: a multicenter international retrospective analysis in a large cohort of patients. J Interv Card Electrophysiol. 2017;49(2): 173-80.

14. Ciconte G, et al. Single 3-minute freeze for second-generation cryoballoon ablation: one-year follow-up after pulmonary vein isolation. Hear Rhythm. 2015;12(4):673-80

15. Evranos $B$, et al. Predictors of atrial fibrillation recurrence after atrial fibrillation ablation with cryoballoon. Cardiol J. 2013;20(3):294-303.

16. Nedios $\mathrm{S}$, et al. Characteristic changes of volume and three-dimensional structure of the left atrium in different forms of atrial fibrillation: predictive value after ablative treatment. J Interv Card Electrophysiol. 2011;32(2):87-94.

17. Fatema $\mathrm{K}$, et al. Minimum vs. maximum left atrial volume for prediction of first atrial fibrillation or flutter in an elderly cohort: a prospective study. Eur J Echocardiogr. 2009;10(2):282-6.

18. Russo C, et al. Left atrial minimum volume and reservoir function as correlates of left ventricular diastolic function: impact of left ventricular systolic function. Heart. 2012;98(10):813-20.

19. Yamano $\mathrm{M}$, et al. Impact of left ventricular diastolic property on left atrial function from simultaneous left atrial and ventricular three-dimensional echocardiographic volume measurement. Am J Cardiol. 2017;119(10):168793.

20. Canpolat U, Aytemir K, Ozer N, Oto A. The impact of cryoballoon-based catheter ablation on left atrial structural and potential electrical remodeling in patients with paroxysmal atrial fibrillation. J Interv Card Electrophysiol. 2015:44(2):131-9.

21. Evranos B, et al. Increased left atrial pressure predicts recurrence following successful cryoablation for atrial fibrillation with second-generation cryoballoon. J Interv Card Electrophysiol. 2016;46(2):145-51.

22. Neumann T, et al. Cryoballoon ablation of paroxysmal atrial fibrillation: 5year outcome after single procedure and predictors of success. Eur Eur Pacing, Arrhythmias, Card Electrophysiol J Work Groups Card Pacing, Arrhythmias, Card Cell Electrophysiol Eur Soc Cardiol. 2013;15(8):1143-9.

23. Badano LP, et al. Left Atrial Volumes and Function by Three-Dimensional Echocardiography: Reference Values, Accuracy, Reproducibility, and Comparison With Two-Dimensional Echocardiographic Measurements. Circ. Cardiovasc. Imaging. 2016;9(7)

24. Cameli M, Mandoli GE, Loiacono F, Sparla S, lardino E, Mondillo S. Left atrial strain: a useful index in atrial fibrillation. Int J Cardiol. 2016;220:208-13.

25. Yasuda $\mathrm{R}$, et al. Left atrial strain is a powerful predictor of atrial fibrillation recurrence after catheter ablation: study of a heterogeneous population with sinus rhythm or atrial fibrillation. Eur Heart J Cardiovasc Imaging. 2015; 16(9):1008-14.

26. Sarvari Sl, et al. Strain echocardiographic assessment of left atrial function predicts recurrence of atrial fibrillation. Eur Heart J Cardiovasc Imaging. 2016;17(6):660-7.

Ready to submit your research? Choose BMC and benefit from:

- fast, convenient online submission

- thorough peer review by experienced researchers in your field

- rapid publication on acceptance

- support for research data, including large and complex data types

- gold Open Access which fosters wider collaboration and increased citations

- maximum visibility for your research: over $100 \mathrm{M}$ website views per year

At $\mathrm{BMC}$, research is always in progress.

Learn more biomedcentral.com/submissions 